\title{
LILIA RAMOS, ESCRITORA Y MAESTRA
}

\author{
POR \\ YADIRA CALVO \\ Universidad Autónoma de Centro América, Costa Rica
}

Cuando la pequeña Jacoba tenía cuatro años vivió la primera rebelión de su vida. Le parecía que ya era bastante ingrato ser pobre y poco agraciada para cargar también con el peso de un nombre «de vieja», heredado de su abuela. Como le pidiera a su madre que se lo cambiara y aquélla se negase, argumentando que la abuelita se entristecería, la pequeña le manifestó, con la despreocupación propia de la niñez: «Entonces debo esperar su muerte.»

No esperó mucho, ciertamente, porque un año después la anciana falleció. Poco más tarde, cuando su padre fue a matricularla al «kinder», al oír que preguntaban por su nombre, adelantándose a la respuesta de su progenitor, la chiquilla se apresuró: «Me llamo Lilia Ramos Valverde.» En aquel momento, con un acto de precoz autoafirmación, se empezaba a gestar la vigorosa personalidad de una de las escritoras más reconocidas en las letras de Costa Rica.

La defensa constante de su individualidad la enfrenta a su madre en su tierna infancia: castigada por haber roto un trasto, se yergue ante ella con un grito y un trozo de loza en la mano, que logra detener la amenaza del golpe. Esta reacción modifica en adelante las relaciones entre las dos, y, según la hija, ambas llegan a un entendimiento. Pero Lilia siguió para siempre por la vida con su grito y su trozo de loza, defendiendo su integridad, su dignidad y su empresa de cultura, siempre dispuesta a detener los embates y las amenazas, que fueron por lo menos tantos como los homenajes y los honores.

Tiene sólo catorce años la chiquilla cuando muere la madre, durante su sexto parto, y los niños se ven repartidos entre unas tías, que Lilia vio como mujeres secas y dictadoras; poco tiempo después, el padre se vuelve a México, su tierra natal, y desaparece, sin rastro, de la vida de sus hijos. 
Unas cuantas cartas al principio, y después el silencio. Lilia recuerda ese periodo de su vida como época de un patetismo convulsionador en la que los cinco hermanos, huérfanos, conocieron la miseria y el infierno personal.

Pero, a pesar de la tragedia, la familia sobrevivió. Lilia cuenta ya con ochenta y un años en el momento en que esto se escribe; es todavía activa, lúcida y luchadora; tiene una cultura general extraordinaria; continúa llevando su vida de tertulias intelectuales, de conferencias, de actividad cultural; conserva la pluma a la mano como otras ancianas las cuentas con que desgranan oraciones, y de ella siguen saliendo páginas llenas de sus recuerdos, de sus fantasías, de su contagiosa calidez.

Graduada de maestra en el Colegio Superior de Señoritas en 1922, y como no encontrase posibilidad de ejercer, se inscribe en el Liceo de Costa Rica para obtener su Bachillerato en Ciencias y Letras. Allí, más que las lecciones regulares, en las que resulta siempre especialmente aventajada, es la amistad con el profesor Carlos Gagini, escritor y filólogo, la clave de su formación. Con él aprende lingüística, literatura, griego, latín... y hasta esperanto, porque Gagini la singulariza con su amistad paternal, la recibe en su casa y la deja zambullirse en su biblioteca (donde se refugia ella con Mariana, sobrina e hija adoptiva del maestro) en persecución de Martínez Sierra, de Lamartine y, sobre todo, de Pérez Galdós, cuyos Episodios nacionales son el tema principal de diálogo en el reducido grupo.

En 1924 obtiene una plaza de maestra en la Escuela Vitalia Madrigal, de San José. Por esa época empieza a escribir piezas teatrales para niños, las cuales se representan en escuelas de Heredia y de San José, con éxito notable. Una de ellas se publica en la Revista de Guatemala. Al mismo tiempo que enseña y escribe, Lilia empieza a preocuparse por los chiquillos menesterosos, para quienes consigue el auxilio de varios médicos, que los atienden gratuitamente. Funda también una escuela para padres, con el fin de enseñar a los adultos el amor a los niños. Entonces sus acciones comienzan a enfrentarse al juicio malintencionado de las gentes, que la califican de librepensadora, lo cual, en Costa Rica, por esos años, resultaba un cargo casi tan grave como ser sospechoso de herejía cuando la Santa Inquisición.

Una beca obtenida en reñido concurso la lleva a Santiago de Chile en 1929, época de la dictadura de Carlos Ibáñez. Allí, como delegada del Instituto Pedagógico en la Federación de Estudiantes, pronuncia, en una asamblea, un violento discurso, a finales del treinta, contra las arbitra. riedades del régimen a raíz de una huelga estudiantil. Sumado a eso, poco después del paraguazo propinado a un carabinero que maltrataba 
a un compatriota, se convirtió en sujeto de vigilancia permanente. Lilia no transige con el despotismo y regresa al país sin haber concluido sus estudios, lo que no obsta para que se le ofrezca una cátedra en la Escuela Normal de Heredia como profesora de Ciencias Educativas y Literatura. Un año más tarde, el ministro de Educación, Teodoro Picado, destituye a aquella profesora por atreverse a declarar públicamente que la Liga de las Naciones era un mito, y encima, como si fuera poco, abogaba por la educación sexual para alumnos y padres. La envían a donde "pueda hacer menos daño», a un kindergarten. De este modo, pasa a formar parte del personal de la Escuela Maternal Montesoriana, que dirige la escritora Carmen Lyra.

Como nada la desanima, allí, con grandes dificultades económicas, Lilia vuelve a empezar: Dedica sus horas libres al estudio. Secretaria del psicoanalista húngaro Antonio Bruck, se convierte en su discípula y obtiene con éxito la rehabilitación de personas con perturbaciones emocionales.

Un día, conversando con el ministro de Educación Pública, Luis Demetrio Tinoco, sobre la necesidad de fundar escuelas para padres de familia, éste atribuye la obra De la Educación Popular a José Martí. Lilia, cuya altivez y sinceridad desconcertaban a sus superiores, le rectifica: «De Sarmiento, señor». Pero ella ignoraba que a un ministro no se le puede corregir impunemente, y poco después la incauta profesora recibe su sanción en la forma que menos lo esperaba: a solicitud de una maestra de sexto grado, Lilia impartía en el grupo de aquélla, por pura buena voluntad, lecciones de Lengua y de Matemáticas, disciplinas en que la maestra le había pedido ayuda. Un día, alguien la acusó de manifestar en clase que Costa Rica «estaba obligada a consultar a Washington las resoluciones trascendentales de política internacional». El señor ministro le envía una amonestación; el director de la escuela y la maestra oficial del grupo investigan con los alumnos el origen del infundio; y aunque de lo averiguado no se obtuvo un solo dato en apoyo de las imputaciones, el rumor ya había levantado vuelo, y así como antes se la acusó de librepensadora, ahora se la etiquetaba de comunista.

Pero ella pasa por sobre las injusticias y las acusaciones como los antiguos mártires cristianos por sobre las brasas: sin sufrir daño. Los golpes no la desaniman, y continúa haciendo lo que cree debe hacer, ajena al celo de ministros insidiosos y a la infame oficiosidad de sus calumniadores.

En 1943 obtiene una beca que le permite estudiar Ciencias Humanas y Tiflología en la Universidad de Columbia y en el New York Institute for the Education of the Blind. Recibe cursos de psicoanálisis en la New School for Social Research. Entre 1945 y 1947 practica y estudia en el 
Institute of Living, Hartford, Conn., donde adquiere el diploma de Auxiliar de Psiquiatría y Educación Terapéutica.

Regresa a Costa Rica en uno de los momentos más convulsivos de nuestra historia, en 1947, cuando se preparan los sucesos políticos que culminan con la Revolución del 48. Se contrata como psicóloga en la Escuela Profesional Femenina, y cuando la escuela se cierra, en 1949, acepta en Guatemala un contrato para organizar asesoramiento a educadores, padres y estudiantes durante tres meses.

Publica en 1950 Cabezas de mis niños, cuya gran aceptación la compensa, al menos, del dolor de no hallar un solo centro docente en su país que no rechace sus servicios en el campo de su especialidad. Al fin, en 1951, y hasta 1954, la nueva psicóloga encuentra acomodo... como Jefe de Publicaciones del Ministerio de Educación. Este empleo no favorece especialmente el aprovechamiento de su saber en el campo de la psicología, pero la pone en contacto con el mundo de las editoriales y de los autores y propicia su vocación de escritora. Aunque no consigue ejercer en el campo de su especialidad, en cambio dirige desde el Ministerio la revista El Maestro, de la que escribe los editoriales y algunos artículos. Por entonces su nombre empieza a rebasar las fronteras del país, especialmente como conferencista sobre temas de educación y salud mental. Hacia 1952 publica la obra de psicología práctica Si su hijito... y sus Cuentos de Nausicaa.

En 1954 viaja a Francia y realiza estudios en la Sorbona, en las Escuelas Martenot y en la Asociación Montessori; colabora en la obra de psicoterapia del Centro de Orientación Universitaria de París; viaja por varios países europeos y por el norte de Africa; se relaciona con el psicoanalista francés Charles Baudouin, quien la hace miembro del Instituto de Psicagogía y Psicoterapia de Ginebra, presidido por él; colabora en el Hospital San Pablo de Barcelona en la rehabilitación de menores con perturbaciones afectivas, y, finalmente, regresa a su país a finales de 1956.

Tres años más tarde colabora en la fundación de la Editorial Costa Rica y en la de la Asociación de Autores. A las pocas semanas de fundada la Editorial es elegida para su presidencia. Por esta época escribe una obra de recuerdos y relatos de sus viajes: Ante mí el dulce milagro. En 1960, en su cargo de Jefe de Publicaciones del Ministerio de Educación y de la revista Educación, realiza una magna labor educacional. Edita La voz enternecida y dos antologías: Júbilo y pena del recuerdo y Luz y bambalinas. Publica también algunas curiosidades bibliográficas de gran valor y varios opúsculos. La Asociación de Autores la nombra, con Fernando Volio y Alberto Cañas, su presidenta honoraria vitalicia en 1963. 
Un año más tarde obtiene el premio «Aquileo Echeverría» por su obra Lumbre en el hogar.

En 1966, después de cuarenta y cuatro años de servicios al país, es destituida de su cargo en el Ministerio de Educación. Renuncia un año más tarde a la presidencia del Consejo Directivo de la Editorial Costa Rica, se dedica al trabajo de editora independiente y publica, entre otras obras de diversos autores, su novela infantil Almófar, hidalgo y aventurero. Al mismo tiempo empieza a escribir Fulgores en mi ocaso, que publica en 1978 bajo el sello de la Editorial Costa Rica. Nuevos viajes entre 1968 y 1970 sirven para complementar el material de este libro, que representa, a mi modo de ver, la mejor y más lograda de sus creaciones.

Si bien la personalidad de Lilia Ramos, altiva, recta y valerosa, le ha atraído, a la par, profundas simpatías y acres antagonismos, su obra, en cambio, recibió siempre el elogio unánime y disfruta de un prestigio nunca puesto en duda. Como autora, Lilia cultiva paralelamente el ensayo científico didáctico sobre psicología práctica, la literatura infantil y las impresiones, relatos y memorias.

Sus obras de carácter psiquiátrico son reconocidas por la originalidad con que presentan los temas. En ellas, su mayor acierto, a juicio del filósofo Constantino Láscaris, consiste en «mantener la seriedad académica de la exposición con la agilidad didáctica para conducir al lector», en un trabajo que anuncia, desde los mismos títulos, «la preocupación por la labor eficaz más que por el análisis teórico abstracto» ${ }^{1}$.

Lilia Ramos es, ante todo, maestra, en el más noble sentido del vocablo. El mejoramiento de sus congéneres ha sido preocupación fundamental suya desde el aula, desde el libro, desde el podio, desde su labor editorial. Por ello, a veces, en su obra infantil emerge cierta tendencia pedagógica, sobre todo en relación con el manejo idiomático.

Podrá discutirse la validez de lo didáctico en la literatura infantil, pero es lo cierto que los libros de Lilia para niños son leídos con gusto hasta por los adultos, porque tienen el mérito de estar muty bien escritos, y en ellos, aparte de que asome con frecuencia la maestra tras la pluma de la autora, los relatos son hermosos y están bien aliñados; algunos, teñidos con una tenue colaboración poética, con figuras inolvidables como la del gigante Palemón de los Cuentos de Nausicaa, quien, por regalar cintas de colores a las hadas, dispara saetas contra el arco iris y lo rompe, provocando una inundación de partículas multicolores que transforman y embellecen la tierra; figuras como el hada Golondrina Viajera, que, irisada

${ }^{1}$ Constantino Láscaris, Desarrollo de las ideas filosóficas en Costa Rica (San José: Editorial Costa Rica, 1964), p. 552. 
y reluciente por haberse zambullido en el mundo de una pompa de jabón, roza a sus hermanas al ejecutar una danza para celebrarlo, y al hacerlo, les transmite el prodigio a sus trajes blancos y a sus zapatitos de cristal.

Lo que hay de pedagógico en los relatos infantiles de Lilia son las explicaciones insertas en los cuentos a fin de instruir a los niños o aclararles vocablos cultos, tal como cuando, en el relato de Palemón, el hermano del héroe, Pitocles, lo quiere convencer de que su intento es inútil porque el arco iris «es un meteoro, algo que se puede ver en el cielo y que resulta de cambios que sufren los rayos del sol al encontrarse con las nubes y las gotas de agua suspendidas en la atmósfera después de la lluvia» ${ }^{2}$. Y en este intento consciente de educar (que, por lo demás, podría suprimirse sin deterioro del relato), Lilia le pone riendas a su vis creadora, olvidando que el cuento busca, como lo manifestó su amiga Dora Isella Rusell, «redimir por la fantasía las grietas de la vida cotidiana» ${ }^{3}$.

Es, sin duda, su acendrada vocación pedagógica lo que le impide a Lilia olvidar, cuando escribe, su condición de maestra, y éste es el mayor reproche que se le puede hacer como escritora para niños. Pero hay que reconocerle, en ese campo, lo que sus críticos y comentaristas concuerdan en atribuirle: la claridad y pulcritud de su estilo, producto de un trabajo depurador del idioma en la justeza de los vocablos y en la corrección de la sintaxis.

Ella conoce el arte sutil de contar cuentos y de construir mundos fantásticos breves, poéticos y lineales, como quieren los niños. Así, en su Almófar, hidalgo y aventurero, se narran las aventuras de un duende que un día, durante un paseo solitario, da con una senda que lo conduce a la superficie del planeta, donde se encuentra con la ardilla Pimpinela. Juntos viven toda suerte de fantásticas aventuras en un mundo lleno de belleza y felicidad, en el que Cinzolín, la más pérfida de las brujas, resulta ser la bondadosa india Rabinjá Rabinzul, hija del río y de la montaña, disfrazada de bruja y convencida de serio por la sugestión de Espelunca Taruga, a quien en su juventud sirvió; y el Bosque Endiablado que rodea su vivienda se transforma, con sólo cambiarle de nombre, en el Bosque Luminoso, y en el que, en fin, la magia del Mago del Otero Azul no es otra cosa que sentido común y buena voluntad, porque no hay magia más poderosa para un escritor que la de las palabras, capaces de construir mundos y seres con vida permanente o al menos mucho más duradera que la de aquel que se las concedió.

${ }^{2}$ Lilia Ramos, Cuentos de Nausicaa (San José: edición particular, 1952), p. 16.

${ }^{3}$ Dora Isella Rusell, Retorno a su cálida ternura (San José: Sección de Publicaciones Ministerio Educación Pública, 1960), pp. 8-9. 
Por eso los personajes de Almófar: Capuz, Papahígo, Fazoleto, Pimpinela... y el duende que le da nombre al libro, seguirán para los niños en la Morada Fantástica de Nuezlandia, como sigue para ellos la Caperucita en el bosque o la Cenicienta en el baile del palacio real. Y es que contar cuentos, o escucharlos, es uno de los mayores placeres con que se puede gozar nuestra mente fabuladora. Y cuando esos cuentos están hábilmente narrados, el gusto por ellos se hereda a través de las generaciones, que los convierten en un legado de la humanidad.

En Costa Rica, los niños entran en el mundo literario con el regocijo de los Cuentos de mi tía Panchita, en que la genial Carmen Lyra recoge relatos del patrimonio universal y los vierte en un lenguaje popular costarricense, haciéndolos nuestros. Porque, aunque, según cuenta la autora, su tío Pablo, el profesor de Etica y Lógica, los calificaba de cuenteretes y bozorola, ella, y con ella todos nosotros, prefería estos relatos de la tía Panchita, ajenos a veces a la gramática y ayunos casi siempre de esas dos cosas que el tío Pablo enseñaba, a los cuentos moralizantes y graves que nos escatiman el puro goce del relato, para ofrecernos lo que cualquier libro de texto nos puede proporcionar.

En una línea diferente, Lilia Ramos continúa, junto con otros autores, la tradición del cuento infantil, no ya popular ciertamente; esta vena, al parecer, se agotó en Costa Rica con Carmen Lyra y con María Leal de Noguera. Lilia crea un cuento erudito, a veces enraizado en la tradición clásica greco-latina; a veces, en la herencia feérica que, quién más quién menos, manejan todos los autores para niños, y, por último, una parte sustancial que da vida a sus personajes es la observación de la naturaleza que nos rodea, y en ella, sobre todo, la de los animales, cuya veta de riqueza narrativa ya habían descubierto siglos atrás los fabulistas.

Pero Lilia los bautiza con nombres eufónicos y onomatopéyicos, sonoros como instrumentos musicales. Los inocentes pollitos Pon Pon y $\mathrm{Pa}$ nina; Vulpeja, la zorra mala; el pato impostor Hopas Hopalanda; el mimoso cerdito Castañuelas y el abejoncito Risco de los Cuentos de Nausicaa, no son, en sus textos, exactamente el genérico animal de las fábulas, caracterizado por un rasgo único y definidor que encarna un vicio o una debilidad humana o una virtud: son todos individuos diferenciados y no una representación de condiciones eternas del hombre, a excepción de los clásicos tía Zorra, tío Conejo y tío Coyote del cuento "Tía Zorra envidiosa», único relato en que la autora echa mano a la tradición literaria del cuento popular.

Con esta herencia preciosa en las manos: la greco-latina, la del cuento de hadas y la que inaugurara Esopo veintiséis siglos atrás; con su simpatía y respeto por los niños, con su vastísimo saber, Lilia Ramos edifica, para 
ellos, mundos ajenos al dolor y al desengaño. Porque para eso, para el dolor y el desengaño, le basta con escribir sobre ellos.

La experiencia que vivió durante dos años como maestra de «chiquitos cinco y seisañeros», como ella dice, le dejó, nos dejó, Cabezas de mis niños, libro en que relata los hondos pesares de aquellos de sus alumnos que llegaban a la escuela con su cotidiana ración de sufrimiento camuflado de violencia, de jactancia, de desconfianza, de estultez... José Luis, Pablo, Hilda, Cecilia... chiquillos para perder la paciencia, cuyos mohínes y malcrianzas usualmente llevan en la tarjeta de calificaciones el equivalente numérico de la desaprobación, son para esta maestra compasiva y conocedora del alma la verdadera razón de ser de su labor educativa. Y son algo más: «porque hablar, escribir, comunicar, es una liberación» ${ }^{4}$, se convierten en personajes de su obra. Por eso José Luis, Hilda, Pablo, Cecilia... siguen siendo, para nosotros, niños sufrientes y famélicos de pan o de cariño, lo mismo da, en las páginas de la amorosa maestra que sufrió con ellos la tristeza de no poder cambiar a un padre egoísta, a una madre díscola, una familia destrozada, un ambiente misérrimo, una vida macerada en la desesperación.

Así como en los cuentos infantiles la pluma de la escritora aparece con frecuencia sostenida por mano de maestra, los relatos para adultos de su volumen Las voces truncas se adivinan contados por la sensibilísima psicóloga que se cuela en los casos perdidos del sanatorio en que trabajó, para dejarnos evidencia, como lo señala Esmeralda Jiménez, de «los terribles mecanismos de los que se vale el hombre para aniquilar a los débiles $0[\ldots]$ los subterfugios que buscan los carentes de iniciativa, los obnubilados con sus propias aberraciones para devastar o minar la estabilidad del fuerte» ${ }^{5}$.

El sensitivo Leonardo, la cruel Miss Flavia, el escritor de apócrifos Nombela, el artífice Alejo Riva y tantos otros seres torturados dejan su marca de angustia en esta obra, como prueba irrefutable de los peligros de la incomunicación, porque, truncas las voces, se trunca también la felicidad.

Una tendencia natural en el lenguaje literario de Lilia Ramos, especialmente acentuada en esta obra, es el empleo de expresiones concisas, nominales, con abundantes enumeraciones de nombres sustantivos y la

${ }^{4}$ Lilia Ramos, Cabezas de mis niños (San José: Editorial La Nación, 1960), p. 12.

${ }^{5}$ Lilia Ramos, Las voces truncas (San José: Edit. Autores Unidos, 1980), pp. 8-9. 
consecuente rapidez de su sintaxis, fenómeno este intensificado, además, por la factura de sus oraciones, por lo general simples, coordinadas o yuxtapuestas. Un fragmento, elegido al azar, del relato «¿Dónde estás, ego mío?», incluido en la obra que aquí se comenta, ilustra parcialmente las anteriores afirmaciones:

Noche brillante en el Teatro de la Opera con Tristán e Isolda. Vibraciones, suspiros, lágrimas al unísono de los dos hermanos. Es tarde y quieren reposar. Muy grande la atracción de la Ermita y se dirigen para una simple ojeada. Un ramillete de cuentos alemanes en edición de lujo adorna la consola. Ella lo vislumbra y entera a Pablo de esa última adquisición, y en el índice, él señala un nombre: La sangre de los Waslungos y... el anzuelo: Thomas Mann. Regina lee. Historia ardiente de unos mellizos - Segismundo y Siglinda-- que se desenvuelve en la atmósfera sui generis del autor. En la segunda parte, el relato va. caldeándose y asciende hasta el paroxismo. Y sucede lo inesperado: el epílogo estremecedor que los impacta, los azora. Se medio reponen... «Sueña con los ángeles» y de estampía, cada mochuelo a su olivo para... insomniar casi en delirio (p. 96).

Por la gran incidencia de recursos que contribuyen a la rapidez sintáctica en Las voces truncas, esta obra produce un efecto huracanado y áspero, en acuerdo con los sucesos que en ella se relatan: vidas deshechas por la infelicidad, lastradas por la neurosis, cargadas sin remedio, como Sísifo, con una roca, cuesta arriba y para siempre, porque en Las voces truncas la autora reunió, de su experiencia psiquiátrica, un manojo de seres que nadie pudo redimir.

Como contrapartida a esta obra de ficción que abrevó de cerca en la realidad, y más que eso, en la verdad del alma enferma, Lilia escribe Donde renace la esperanza, obra de contenido "verídico en toda su longitud», como aclara ella en el «Umbral», y basada en su experiencia profesional en el Institute of Living, hospital neuropsiquiátrico de Hartford, Nueva Inglaterra. Escrita con gratitud hacia el lugar donde aprendió a conocer la conducta patológica y los métodos para su recuperación, Donde renace la esperanza reúne anécdotas, historias, acotaciones y episodios de la vida cotidiana en aquel centro, que llama «huéspedes» a sus pacientes no por simple eufemismo, sino porque su director conocía la influencia que ejercen en el alma las palabras.

Con gran habilidad, la autora nos conduce al inmenso parque donde se desenvuelve la vida del Institute of Living, entre conciertos, exposiciones, conferencias, paseos y también, a ratos, tiernos y jocosos episodios «de locos», como aquel en el que dos esposos, internados en diferentes 
épocas en el sanatario, se encuentran un domingo al salir de la capilla, a pesar de las precauciones que se han tomado para evitarlo. Ante la consternación de los auxiliares, se dirigen uno al otro:

- ¡Dan, mi querido! ¿Por qué has tardado en volver a casa? ¡Los niños están muy nerviosos!

-iJean, mi amor! Lamento haberla preocupado... la oficina estaba llena de clientes... ¡Regresemos! ${ }^{6}$

Interesan en esta obra las acotaciones, porque en ellas se ilustran ciertas patologías con los nombres de famosas personalidades que las padecieron; y el saber que una grave enfermedad mental no ha obstaculizado la producción de obras creativas tan estimables como las de Kafka, D. H. Lawrence, Van Gogh, Dostoievski, Virginia Woolf, los Nodier..., por citar sólo algunos de los creadores que menciona Lilia en su obra, confirma el cumplimiento de su propósito al escribirla: la utilidad de «enseñanzas aplicables a un mejoramiento personal y a una comprensión del mundo complejo, oscuro y trágico de los infelices que no han aprendido el arte de vivir» (p. 10).

Menores sólo por la extensión son sus opúsculos $\mathbb{E} l$ santo enamorado de los humildes, breve biografía de Vasco de Quiroga; Nueva York, metrópoli sideral, especie de guía para el viajero instruido, y Mensaje en claridad inefable, que bien podría subtitularse «Elogio de la sardana». En esta obra, que tiene la extensión apenas de un artículo, aunque se editó en forma de libro, se describe la ejecución de la danza popular de Cataluña, en la que Lilia encuentra reminiscencias de frisos y vasijas griegas. Bello el lenguaje, penetrante la observación, la obrita es una brevísima muestra de la habilidad descriptiva de su autora.

Más extensa su Evocación del Greco, escrita en colaboración con Lolita Zeller de Peralta, con abundantes evocaciones autobiográficas de su propio paso por Toledo, que Lilia describe como «inolvidable gracias a los toledanos generosos y cultos» que conoció, y donde el último y más preciado recuerdo resulta ser no la casa del pintor ni su obra inmortal, como pudiera creerse, sino simplemente los niños que le hablaron «con fervor de El Greco, a la luz de un ocaso violeta» ${ }^{7}$.

Por último, y antes de dar un vistazo a la obra más interesante de Lilia Ramos, es necesario referirse a su labor de antóloga, sobre todo en dos obras de gran valor para la cultura costarricense; Júbilo y pena del

${ }^{6}$ Lilia Ramos, Donde renace la esperanza (San José: Ediciones Elite, 1963), p. 10.

${ }^{7}$ Lilia Ramos y Lolita Zeller, Evocación del Greco (San José: Imprenta Metropolitana, 1966), p. 44. 
recuerdo y $L u z$ y bambalinas. Esta última contiene cincuenta y ocho textos teatrales infantiles que conforman, en criterio de su prologador Guido Fernández, «una selección cuidadosa de piezas dramáticas tendientes a facilitar al niño sus contactos más elementales con el teatro, a fin de que mediante este sistema tan eficaz pueda afinarse su sensibilidad y se vaya formando un sedimento cultural susceptible de ser aumentado durante su trayectoria por la Escuela» ${ }^{8}$.

Júbilo y pena del recuerdo recoge evocadoras páginas de la historia patria, no de la ciencia de la historia, que relata los sucesos bélicos y políticos y los nombres señeros de quienes los protagonizaron, sino la historia humilde y sin bombo del vivir de cada día, que se queda por fuera de los libros y de los archivos y constituye, sin embargo, el más precioso dato para juzgar la verdadera circunstancia de una época y un país. Sus páginas se pueblan con los modestos seres que ocuparon los márgenes de los hechos memorables y con aquellos a quienes, actividad o particularidades, los fijan en un momento del pasado. Allí la madre de Juan Santamaría, el héroe nacional de Costa Rica, la casi menesterosa Manuela Carbajal, «de oficio mugeril» y avecindada en Alajuela, suplicando al presidente de la República «una mirada compasiva», «un monte pío», obligada. por la «necesidad imperiosa» de no dejarse morir de hambre; allí «El curandero», de Jenaro Cardona, que descubrió el secreto de curar enfermedades con medicinas cuyos nombres empiezan por la misma letra que el del mal; allí, en páginas de Carlos Jinesta, el San José de 1891, que se estrena de urbe «con visibles empujes de adelanto», como calles tiradas. a cordel y conferencias sobre Platón en la Escuela de Derecho; allí, en fin, la vida de Costa Rica en el bullir cotidiano y ordinario del país tranquilo. y sencillo de principios de siglo, que tenía por elegancia el desfallecimiento de las señoritas de alta sociedad y el sombrerazo de los caballeros en la calle, y por máxima diversión capitalina la misa de tropa con banda militar, la retreta, uno que otro circo perdido alguna vez por estas zonas. y los bailes de gran rumbo en el Teatro Nacional.

Júbilo y pena del recuerdo, en cuanto sintetiza, en muchos aspectos, la esencia de lo costarricense, no es simplemente una antología: es La Antología: compendio único que conserva vivos, en un solo volumen, retazos del mundo que gozaron y sufrieron los abuelos, desperdigados antes por revistas y publicaciones de escasa perdurabilidad, cuidadosamente recortados y cosidos por Lilia hasta formar una magnífica pieza trabajada con esmero.

$$
* * *
$$

${ }^{8}$ Lilia Ramos, Luz y bambalinas (San José: Editorial Costa Rica, 1982), p. 10. 
Toda esta 1abor, en el campo de la cultura, ha sido reconocida públicamente a Lilia no sólo en el país: en 1964 obtiene el premio «Aquileo Echeverría» por su Lumbre en el hogar; en 1978 se le confiere el «Magón» por la obra ingente de toda una vida dedicada a crear, impulsar y prohijar la cultura costarricense; en 1975, la Asociación de Escritores del Interior y la Asociación Uruguaya de Autores crea el premio «Lilia Ramos» en honor a sus méritos. Todo esto, aparte de gran cantidad de homenajes y reconocimientos de carácter menos espectacular.

Para otros autores eso podría significar una obra terminada y el consecuente descanso. Para Lilia, no. Ella podría, con propiedad, exclamar, como la francesa Colette: «Pero ¿cuándo se deja de escribir? ¿Cuál es el aviso? ¿Un tropiezo en la mano? En otro tiempo creí que el trabajo escrito era como los demás trabajos. Abandonado el utensilio, se exclama alegremente: iAcabado!, y uno se frota las manos; de dónde llueven los granos de una arena que se ha creído preciosa... Es entonces cuando en las figuras que escriben los granos de arena se leen las palabras: 'Continuará'....»?

Como Colette, Lilia continuará porque, como manifiesta el doctor Jorge Vega, «ella nunca se acaba». Por eso, porque lo abúlico y lo añejo le son desconocidos, ha sido capaz de ponerse a escribir, a los sesenta $y$ cuatro años, una obra que le llevaría un decenio y que daría un resultado proporcional al esfuerzo que le dedicó. Fulgores en mi ocaso tiene, sin embargo, un desacierto, según juicio del citado doctor Vega: debió haberse llamado Fulgores en mi lontananza, como puede esperarse de la vitalidad de su autora, quien, en frase de Goethe, asegura que, «a pesar de todo, la vida es bella».

Porque «con los años van quedando recuerdos de recuerdos», la escritora se dedica a recoger esa cosecha de toda una vida cuando ya tiene andada una buena parte del camino, y, espigando entre sus más queridas experiencias, forma un haz apretado en que se juntan despedidas y encuentros, dulzuras y amargor: «Los júbilos para la iteración gloriosa con los sufrimientos, para derivar enseñanza o establecer comparaciones si el destino ha sonreído», dice ella. Su propósito queda claro en el inicio de la obra:

Suelo darme a evocaciones y en ellas siempre van adquiriendo relieve especial los seres que, en una u otra forma, me han enriquecido con sus tesoros espirituales. En general, las páginas de este libro llevan el acento afectivo: son homenaje amoroso a las gentes... ${ }^{10}$

9 Gabrielle Colette, Obra completa (Barcelona: Plaza y Janés, 1965), p. 1571.

10 Lilia Ramos, Fulgores en mi ocaso (San José: Edit. Costa Rica, 1978), p. 11. 
$Y$ esto porque ella ha "saboreado regocijos compensadores al amar a Dios en el regalo de sus criaturas y en la bendición del trabajo»" ${ }^{11}$.

Pero esas criaturas de Dios en las que Lilia le ha amado no son, por cierto, los seres grises y anónimos que pasan sin rastro por la vida: son seres egregios, porque Lilia Ramos, que entiende y conoce el arte de la amistad, vive, como los jardineros aficionados a plantas raras y flores imprevistas, rodeada de seres de singular naturaleza, cuya amistad cultiva con exquisita habilidad. Son estos seres los que pueblan su obra, cada uno con un fulgor cuya luz recoge la autora para formar un haz luminoso de nombres, encuentros, anécdotas, sucesos, diálogos, revelaciones... en que se recoge el matiz íntimo, el gesto de andar por casa, la conversación circunstancial de un escritor, de un pensador, de un artista, o se refleja el rayo luminoso de un espíritu en más modesta encarnación, en quehacer más humilde de puro amor al prójimo. Porque ella hace suyas las palabras de Unamuno cuando afirma que «cada nuevo amigo que ganamos en la carrera de la vida nos perfecciona y enriquece, más aún que por lo que él mismo nos da, por lo que de nosotros mismos nos descubre»: escondrijos y recovecos de la conciencia que no se nos muestran, a no ser que, merced a la comunión espiritual con otras personas, se nos revelen. De estos seres hubo y sigue habiendo coro en la vida de Lilia. Grandes y reconocidos unos, modestos y sin gran renombre otros, pero todos irradiando algún fulgor, cuya luz alumbra los días de la escritora entre la paz y la limpieza de su casa-museo en San José.

Como una nueva máquina del tiempo, Fulgores en mi ocaso da vuelta atrás a la rueda de los años y nos presenta, resucitados, al gigantón genial Max Jiménez y a la hermosa y torturada Yolanda Oreamuno, junto a quienes Lilia confiesa que se siente liliputiense, lo cual no impide que les profese devoción. En el taller de Max, mientras admira dibujos y pinturas, fascinada doblemente por el artista y por el hombre, se sobresalta ante la inesperada aparición de Clemencia, la esposa del pintor. A los sesenta y tantos años nos confiesa ella la razón del sobresalto: estaba enamorada de su amigo. Es posible que en aquel momento sólo ella lo supiera, y es rigurosamente cierto que el sentimiento por el hombre no perturbó la amistad, como no perturbó la envidia los lazos que la unieron con Yolanda Oreamuno. Porque ante aquella mujer bellísima, que «sacude el ambiente de las letras y de las artes» al tiempo que «es vedette en las crónicas sociales», Lilia siente acrecer lo que ella llama la «sensación de minusvalía por mi fealdad». Para empeorar las cosas, se da cuenta del

${ }^{11}$ Jorge Vega, «Generosidad hecha mujer: Lilia Ramos», La Nación, 20 abri1 1979. 
«desafío que significa su obra» y comprende que no puede aceptarlo. Entonces se confiesa ante Yolanda, que ríe con incredulidad y se regocija de esa decisión que marca el comienzo de una amistad sin igual entre estas dos mujeres, una de las cuales, la hermosa, se consumió como un meteoro, dejando su marca de luz en el cielo de las letras hispanoamericanas; la otra vive todavía recibiendo premios, homenajes y condecoraciones, porque, como el patito feo del cuento, a la larga ha terminado por convertirse en cisne.

Memorias y confesiones pueblan las páginas de Fulgores en mi ocaso. Tantas, que no es posible detenerse en su regodeo más que con la lectura misma de la obra. Pero no se puede uno sustraer, al comentarla, de referirse a algunos de sus episodios que mejor pueden perfilar la naturaleza de este libro, tales el referido a sus cuarenta y cinco años de relaciones, «siempre llenas de esos júbilos hondos que endulzan la vida», con el poeta José Basileo Acuña, a quien ella considera su amistad amorosa, desde el tiempo en que, en 1930, a su regreso de Chile, lo tuvo por colega en la Escuela Normal, donde el interés por la psicología los hermanó. Lilia describe sus domingos juntos en la gran casa de Pepe, como ella familiarmente lo llama, a veces con una o dos amigas, entre libros y golosinas preparadas por él:

Yo en un sillón confortable... él, a mis pies sobre un enorme y blando cojín, apacible y muy enhiesto, me traía la imagen de Sakiamuni, hasta que la risa espontánea la alteraba. [...] La media luz del anochecer lo invitaba a confesiones... Yo me abstraía e íntegra oídos era un receptor fiel y ávido... (p. 66).

Pasan los años a puñados, y Pepe y Lilia siguen visitándose, intercambiando libros, queriéndose como amigos entrañables, tal vez porque, como dice él en una de sus poesías, «tan sólo la amistad nos brinda el mundo / como un resquicio para ver el cielo».

No se queda la obra encerrada en el pequeño y estrecho círculo de amigos que forman el mundo intelectual de San José. Por el contrario, se remonta, como lo advierte el doctor Jorge Vega, «desde reuniones casi provincianas alrededor del parque Morazán hasta las estribaciones del Hudson, del Mar del Plata, del Sena, de las planicies mexicanas, las arideces castellanas...» ${ }^{11}$, y en todos los lugares que visitó halló un amigo, halló varios amigos, porque, como dice ella, «el afinador de su espíritu necesita colegas de ensueño y siempre da con varios dispuestos a la aventura gloriosa» (p. 67). Y así, en ese constante peregrinar, llega a Uruguay, donde el amor a las letras la conduce a la casa-santuario de Juana de Ibarbourou, a quien se aproxima con un secreto temor, porque la fama publica 
que Juana ha hecho retirar de su casa los espejos para no enfrentarse a la pérdida de su belleza, lo cual, en sí, no significaría casi nada si no fuera porque retirar los espejos es un acto simbólico de mucha mayor gravedad, del cual hay que inferir que a Juana se le ha envejecido el talento. Con indecible emoción, Lilia llora ante la poetisa de América, que la recibe rodeada de sus espejos y entre «un mar de hojas» de escritura reciente.

Son brillantes las páginas referidas a loan Vidal y a Alberto Fernández Leys, que, gracias a la declarada epistolomanía de Lilia, se doran con fragmentos de cartas de éstos, sus dos amigos: esquelas intimas con dignidad de iextos que no deben quedarse atados con cintas en la gaveta de un secrétaire. Cuando Vidal conoce su decisión de recluirse para redactar sus memorias, le aconseja que se goce toda entera en tan sublime deporte, que «es la sola justificación activa de nuestras vidas, el premio intemporal a su enemiga brevedad» (p. 76). Y Fernández Leys, desde otro punto cardinal del mundo, mediante asidua correspondencia, le confía libros, penas y emociones, que le son retribuidos en moneda del mismo valor. En uno de los fragmentos reproducidos por Lilia escribe Aiberto:

La correspondencia contigo - esta carta por caso- es la que me permite repasar mis ideas, frecuentar mi optimismo, la frescura del pensamiento; el acto de pensar y repensar. Estar de acuerdo con la vida y lo vivido. Y con esta amistad que viene de lejos - honda, emotiva, limpia y entrañable - que hace bella la vida y embellece lo vivido, las horas de hoy y de mañana. He renacido para el afecto con el día de hoy. Quiera la suerte que prevalezca la imagen que de mí tienes. Nada haré por modificarla, bella amiga, maravillosa amiga. iLilia del corazón luminoso! (p. 163).

Leyendo el fragmento epistolar de Ioan Vidal antes reproducido, se comprende mejor por qué escribe Lilia Ramos un libro de memorias: quiso regalarse con ese premio intemporal a la brevedad de la vida, de que Vidal habla, pero como persona generosa que es, nos regaló a la vez su propio mundo, para que también nosotros nos gocemos en él. Y es que, como bien apuntó Constantino Láscaris, esta mujer vive sus libros como una voluntad de mejoramiento. Como una voluntad de mejoramiento los ha de vivir también el lector que los recibe.

La obra escrita de Lilia Ramos, así se ocupe de impartir lecciones prácticas de psicología, de crear mundos fantásticos para los niños o de relatar hechos de su propia experiencia es producto de una estrecha colaboración entre la maestra y la escritora que alientan juntas en todo lo que Lilia Ramos hace y escribe. 
